\title{
EREBEA
}

Revista de Humanidades

y Ciencias Sociales

Núm. 3 (2013), pp. 25-47

ISSN: 0214-0691

\section{LOS OBISPOS FUNDADORES: BIOGRAFÍA, PODER Y MEMORIA EN LA DIÓCESIS DE CUENCA*}

\author{
José Manuel Nieto Soria \\ Universidad Complutense de Madrid
}

Resumen

Hay obispos cuya vida está vinculada con los orígenes de una determinada diócesis. Estos obispos suelen adquirir un valor muy simbólico para la historia de ésta. Durante los siglos XII y XIII se produce un importante avance en el proceso de fundación de nuevas diócesis en Castilla. La mayoría de los datos biográficos sobre los primeros obispos de estas nuevas diócesis están referidos a los principales hechos del proceso de institucionalización diocesana. En este contexto, este artículo estudia el caso de los dos primeros obispos de Cuenca y de sus paralelismos biográficos, destacándose la relación entre biografía, poder y memoria y la importancia histórica del proceso de santificación del segundo de estos prelados.

Palabras Clave

Obispos. Castilla. Cuenca. Biografía. Poder. Memoria. Hagiografía.

Fecha de recepción: 10 de junio de 2013 Fecha de aceptación: 1 de julio de 2013
ABstract

There are bishops whose life is closely linked to the origins of a particular diocese. These bishops tend to be a very simbolic value for the history of their dioceses. During the 12th and 13th centuries a breakthrough occurs in the process of foundation of new dioceses in Castile. Most of the biographical data about the first bishops of these new dioceses are referred to the main acts of the Diocesan institutionalization process. In this context, this article explores the case of the first two bishops of Cuenca and their biographical parallels, emphasizing the relationship between biography, power, and memory and the historical importance of the process of sanctification of the second of these prelates.

\section{KEYWORDS}

Bishops. Castile. Cuenca. Biography. Power. Memory. Hagiography.

* Este trabajo forma parte del Proyecto no HAR2010-16762 de la Secretaría de Estado de Investigación. 

En una fecha todavía tan relativamente cercana como 1989 Marc Ferro utilizaba una expresión bien contundente, a la par que descriptiva, para dar título a un artículo suyo referido al género biográfico: "La biographie, cette handicapée de l'histoire"l. Apenas cinco años después, puede leerse un interesante trabajo de Bernard Pudal en el que sitúa la valoración de la biografía entre las opciones que ofrecen la ciencia y la ficción ${ }^{2}$; siendo términos bastante similares los empleados recientemente por François Dosse para referirse a la misma cuestión ${ }^{3}$. En este sentido podrían extenderse desmesuradamente las referencias limitándonos tan sólo apenas a la última década, en la que, no obstante, por diversas razones que no vienen al caso, se ha producido una evidente expansión del género ${ }^{4}$.

Pues bien, si la biografía ya de por sí ha generado un importante conjunto de sombras sobre su plena operatividad historiográfica, éstas se ven inevitablemente potenciadas si nos referimos a épocas en las que, por su distancia y debilidad documental, agregan nuevas delimitaciones específicas al ejercicio del género, más allá de las que éste por sus propios rasgos pueda exhibir, tal como puede suceder para una época, como la que nos va a ocupar, a caballo entre los siglos XII y XIII, en la que la propia idea de lo individual queda sujeta a no pocas cautelas historiográficas ${ }^{5}$.

$\mathrm{Si}$, además, atendiendo a la demanda del director de la publicación que da acogida a este texto, ese sujeto individual, ya de por sí escurridizo y de perfiles poco precisos por lo común para la época indicada, es un obispo, esta condición contribuiría a imponer nuevas delimitaciones, a la vez que a vislumbrar ciertas perspectivas analíticas particulares.

1 Marc Ferro, "La biographie, cette handicapée de l'histoire”, Le Magazine Littéraire, abril, 1989, citado en François Dosse, El arte de la biografia, entre historia y ficción, México, Universidad Iberoamericana, 2007, p. 81.

2 Bernard Pudal, "Du biographie, entre 'science' et 'fiction'. Quelques remarques programmatiques", Politix, 27 (1994), 5-24.

3 DOSSE, ob. Cit.

4 Un breve panorama reciente sobre esta transformación en: François Dosse, "Biographie, prosopographie”, en Historiographies, I. Concepts et débats, C. Delacroix, F. Dosse, P. Carcia, N. Offenstadt, París, Gallimard, 2010, pp. 79-85

5 Aron Gurievich, Los origenes del individualismo europeo, Barcelona, Crítica, 1997. 


\section{FundaCiones ePISCOPALES Y biografía}

La propuesta del profesor Pérez-Embid de abordar alguna biografía episcopal me ha hecho recordar una lectura reciente en la que se evocaban ciertas reflexiones de Gregorio de Tours procedentes de su famosa Historia de los Francos que me parecen oportunas para el caso que nos va a ocupar. En ellas mostraba la construcción de la iglesia franca como el resultado de la memoria de sus mártires, siempre asociados al nombre de una u otra ciudad, así como al nombre de los obispos fundadores de una u otra diócesis. De este modo, la memoria de esos obispos era mucho más que el recuerdo, entre ficción e historia, de un individuo de perfiles casi siempre nebulosos, era también la construcción de una realidad histórica concebida como resultado de lugares e individuos elevados a la categoría de referentes ejemplares de tal o cual virtud o modo de comportamiento ${ }^{6}$. Es por ello que los sepulcros de ciertos obispos, en especial si su existencia se había ubicado en los tiempos inmediatos a la fundación de una diócesis, se convertían en lugares con un valor sagrado ańadido que se conectaba íntimamente con la historia completa de la ciudad en cuestión, dotándola de una seña de identidad singular particularmente relevante, a la par que frecuentemente muy perdurable.

Por otra parte, al menos desde la época carolingia, los obispos desplegaron su actividad bajo tres formas principales de expresión cuya consideración perfila significativamente cualquier intento de aproximación a sus trayectorias biográficas concretas: la carismática, la material y la institucional ${ }^{7}$. La primera, la carismática, conlleva todo lo que afecta a la importante dimensión ritual y ceremonial de la dignidad episcopal. La segunda, la material, incide en el papel decisivo que ejerce el obispo desde el punto de vista de la provisión y administración patrimonial de su iglesia. La tercera sitúa al obispo en una posición privilegiada desde el punto de vista de la articulación de relaciones entre instancias institucionales de naturaleza diversa, entre las que destacan la propiamente eclesiástica (pontificia, episcopal, catedralicia, diocesana, monástica), la concejil y la regia, principalmente. Es la consideración de esa triple dimensión, por tanto, la que delimita los rasgos biográficos esenciales específicos de la condición episcopal tal como las posibilidades informativas de la época nos pueden permitir. A ellos, en el caso de obispos singulares en la evolución histórica de la diócesis y, muy en particular, los que se sitúan en los comienzos de su evolución, se añade aquella otra dimensión relacionada con la propia memoria del prelado que, en no pocas ocasiones, deviene en relato hagiográfico.

En la España Medieval, la creación de diócesis fue, tal como bien se puede testimoniar en el caso de Cuenca, un fenómeno directamente asociado con la propia actividad reconquistadora, no estando sólo dirigido a asegurar la atención

6 Dominique Iogna-Prat, La maison Dieu. Un histoire monumentale de l'Eglise au Moyen Âge, París, Éditions du Seuil, 2012, p. 207-208.

7 Iogna-Prat, 206. 
espiritual de los nuevos territorios incorporados, sino también a convertirse en un factor de consolidación de las conquistas, de articulación de la nueva realidad social emergente y de atracción de nueva población y de impulso de su definitivo asentamiento ${ }^{8}$.

El que las cosas fueran de este modo tenía varias consecuencias que conviene enumerar.

En primer lugar, estaba el que la ocupación de cualquier centro de población medianamente importante se traducía en la creación de una sede episcopal que contribuía a convertir a ese centro de población en ciudad preeminente en un amplio ámbito territorial.

En segundo lugar, destacaba la necesidad de elegir los primeros obispos de estas nuevas diócesis entre personas abnegadas, con gran capacidad de sacrificio y de dedicación a unas tareas que iban, por lo general, mucho más allá del propio ministerio episcopal, entre las que no faltaban, la de índole económica, a fin de incentivar el crecimiento de la ciudad y la puesta en explotación del territorio circundante. Estos personajes debían actuar con frecuencia como mediadores en los múltiples conflictos que surgían en una tierra en proceso de ocupación por gentes de las más diversas procedencias, costumbres e intereses y que durante mucho tiempo permanecía en un inevitable estado de inestabilidad institucional que daba especial importancia a la mediación de individuos socialmente influyentes, tal como debía ser el caso del prelado. Por ello debían dedicar considerables esfuerzos a contener los intereses abusivos de determinados grupos de poder, o, incluso, ponerse al frente de las tropas para defender una frontera que casi siempre resultaba durante algunos años demasiado próxima e inquietante. En tal sentido, la vinculación personal de muchos de estos prelados con el propio monarca permite hablar en no pocas ocasiones de verdaderos hombres del rey.

Finalmente, la tercera consecuencia se refería a cómo el hecho de la fundación de la sede episcopal daba paso a un largo periodo en el que, para hacer efectivamente operativa la institución episcopal, era necesario abrir un proceso de organización muy complejo que, generalmente, se alargaba mucho en el tiempo. Podría decirse que, por término medio, este proceso organizador suponía del orden de cerca de medio siglo, tal como puede verse para el propio caso de Cuenca y de otras diócesis de fundación cronológicamente próxima, como Ciudad Rodrigo (1168) o Plasencia (1189). En todas ellas, vemos cómo, todavía en el último tercio del siglo XIII, se están resolviendo aspectos de importancia decisiva para la organización de la institución diocesana.

8 Referencia obligada para el seguimiento de esta transformación de la geografía eclesiástica peninsular en función de la actividad de fundación de nuevas diócesis: Demetrio Mansilla Reoyo, Geografía eclesiástica de España. Estudio histórico-geográfico de las diócesis, 2 vols., Roma, Instituto de Historia Eclesiástica de España en Roma, 1994. 
Éstas eran cuestiones que abarcaban una amplísima diversidad de realidades tales como la fundamentación de las bases económicas ${ }^{9}$, con la percepción del diezmo y el sistema fiscal de la Iglesia de la diócesis, además de la dotación real y la formación del patrimonio básico, la organización del cabildo catedralicio, la propia construcción de la catedral, generalmente muy costosa y de muy larga duración, las relaciones entre los diversos estamentos clericales, la estructuración de la red parroquial y del conjunto de la estructura territorial de la diócesis, desde los arcedianatos y los arciprestazgos hasta la última de las parroquias, sin olvidarnos de las collaciones-parroquias de la propia ciudad episcopal que articulaban espacialmente el territorio urbano, las formas de asistencia social, el desarrollo de la jurisdicción eclesiástica y de la cancillería episcopal, etc ${ }^{10}$.

Todas estas son labores que, contempladas en su exacta valoración en el contexto de los medios de la época, suponían un esfuerzo hercúleo basado en la actividad de muy pocos hombres, con el obispo como principal protagonista, y que había que realizar en condiciones muy difíciles, entre las que no faltaba la amenaza de un asalto musulmán imprevisto que acabara con la devastación de buena parte de la diócesis o con el secuestro, cuando no asesinato, del propio obispo por las fuerzas islámicas, tal como pasó más de una vez en aquella época.

De toda esta actividad, para los momentos originales de cada diócesis, la información que hoy día se conserva es relativamente pequeña, de modo que generalmente conservamos aquellos documentos que se refieren casi exclusivamente a algunos de los hechos institucionales más relevantes, ni siquiera todos. Muy escasa, en cambio, es nuestra información sobre la cotidianidad de una labor que, en no pocas ocasiones, debía resultar extenuante y de la que los magníficos edificios catedralicios podrían ser considerados como el símbolo visual que nos ha llegado como imagen inmediatamente perceptible de todo aquello.

Es precisamente este tipo de información la que, en esencia, define, en la inmensa mayoría de los casos, lo que son las muy limitadas posibilidades de aproximación biográfica a las figuras de aquellos obispos que formaron parte de la época inicial de la puesta en marcha de muchas de las diócesis que iban surgiendo en sintonía con los avances de las fronteras de los reinos cristianos peninsulares.

Pero, además, hay otro perfil biográfico que no conviene menospreciar, a pesar de la inevitable dimensión mítica que a veces conlleva y que nos sitúa en esa inestable línea fronteriza entre ficción y realidad que con respecto a la biografía señalaba al principio de estas consideraciones. Me refiero a la conexión que se produce entre fundaciones episcopales y puesta en marcha de las nuevas diócesis y

9 José Manuel Nieto Soria, "El equipamiento económico de una sede episcopal castellana de nueva creación: Cuenca 1180-1280", Anuario de Estudios Medievales, 12 (1984), 311-340.

10 Análisis pormenorizado de todo ello en: Jorge Díaz Ibáńez, Iglesia, sociedad y poder en Castilla. El obispado de Cuenca en la Edad Media (siglos XII-XV), Cuenca, Obra Social y cultural de la Caja de Castilla-La Mancha, Editorial Alfonsípolis, Diputación Provincial de Cuenca, 2003. 
la construcción hagiográfica que en torno a ciertas anécdotas y comportamientos se acaba elaborando, bien en la corta o en la larga duración ${ }^{11}$, aportando así otro elemento de caracterización biográfica que, tal como señalaba al principio, entre la historia y la ficción, no deja de tener un relieve histórico que, desde el punto de vista de la creación de señas de identidad local, acaba teniendo una indudable trascendencia en el tiempo.

Será desde este conjunto de perspectivas que acabo de señalar cómo se abordará el caso concreto de los dos primeros obispos de Cuenca que ofrecen, a mi modo de ver, una buena ejemplificación de las posibilidades temáticas recién enunciadas. Pero para que sea posible la aproximación inteligible a estos obispos fundadores en el caso conquense, habrá de ser necesario antes establecer algunas referencias esenciales de los rasgos constitutivos que definieron los orígenes de la iglesia conquense como realidad diocesana

\section{LOS ORÍGENES DE LA IGLESIA DE CUENCA.}

Referirse a los orígenes de la Iglesia de Cuenca, naturalmente, pasa por aproximarnos a dos hechos decisivos en la historia de la ciudad y su tierra: la conquista cristiana y la fundación de la nueva sede episcopal.

\section{A) LA CONQUISTA.}

Habiéndose comenzado el cerco de la ciudad conquense el 6 de enero de 1177 por los reyes de Castilla y Aragón, Alfonso VIII y Alfonso II, respectivamente, hubieron de transcurrir más de nueve meses hasta ver culminada la difícil empresa de su conquista, pudiendo entrar los sitiadores en la ciudad, según unos autores, el 14 de septiembre, o una semana más tarde, según otros, quedando así incorporada a la Corona de Castilla.

Bien poco es lo que se sabe de la Cuenca de aquellos días. De los momentos inmediatos a la conquista conocemos una somera descripción a cargo del cronista almohade Sahib al-Sala, que nos sitúa en el verano de 1172, en que había visitado la ciudad. El mencionado cronista musulmán ofrece la siguiente visión:

"El califa se puso en marcha hasta entrar en la ciudad y en su alta alcazaba, cuya elevación llega hasta tocar las nubes, que muestra aún huellas de la prosperidad que alcanzó en tiempos de los reyes del Islam $y$ del cuidado que éstos pusieron en hacer de ella un fortísimo baluarte para las vicisitudes de los tiempos. La envuelve por la parte occidental el rio Júcar, con bordes escarpados y precipicios que impiden el acceso

11 Múltiples ejemplos de ello en Javier Pérez-Embid Wamba, Hagiología y Sociedad en la España medieval. Castilla y León (siglos XI-XIII), Huelva, Publicaciones de la Universidad de Huelva, 2002, pp. 139-214. 
a ella: y por la parte oriental corre otro río con iguales condiciones de inexpugnabilidad para la plaza; ambos vierten sus aguas en una gran buhayra o lago que provee de agua a sus habitantes y que está contigua a la muralla. Se entra en la ciudad por dos fuertes torreones, sobre ambos rios, en jurisdicción de la ciudad... No hay sitio por donde se pueda atacar esta ciudad más que por el dicho foso y por la al-buhayra"12.

Cabe deducir de esta descripción que, ya por entonces, hacia 1172, los musulmanes conquenses vivían con cierta añoranza el recuerdo de tiempos pasados, de los que debía restar sobre todo el prodigioso baluarte defensivo, tal como se nos describe, pero sin que ni por población ni por actividad, la ciudad viviese sus mejores momentos, lo que era comprensible ante el progresivo avance cristiano, que dejaba a estas ciudades más septentrionales del islam en situación comprometida, lo que provocaría la continuada pérdida de población, quedando ésta limitada sobre todo a los imprescindibles destacamentos militares, de modo que, según un censo elaborado en aquel mismo año, la ciudad no superaría los 700 habitantes ${ }^{13}$, todo ello en un contexto de cierto abandono de posiciones hasta hacía poco muy sólidas para el poder almohade ${ }^{14}$.

Es también en el rasgo de su inexpugnabilidad, sólo superable por la tenacidad y dureza del asedio, en lo que se hace mayor incidencia por parte cristiana, por lo que se refiere a los días de su conquista por castellanos y aragoneses. Así, tal como se nos describe en la Primera Crónica General:

"Çerco (se refiere a Alfonso VIII de Castilla) Cuenca, que era entonces la fortaleza de los alaraves en España. Et aquerexolos con muchos trabajos que les dio: fizo aderredor de Cuenca sus bastidas con muchos engeños et paro y muchas algaradas, et nin les dio vagar de dia nin de noche, de guisa que les vedo las entradas et las salidas fasta que les fallescio la vianda et todo otro consseio".

Así, pues, más que como consecuencia del hostigamiento militar y de los reiterados asaltos, parece que la toma fue, ante todo, resultado del total aislamiento de la ciudad, hasta hacer insostenible su situación.

12 Sahib al-Sala, Historia de los Almohades, apartado 29. Tomado de Claudio Sánchez Albornoz, La España musulmana, Madrid, Espasa-Calpe, 1974, II, p. 296.

13 Salvador de Moxó, Repoblación y sociedad en la España cristiana medieval, Madrid, Rialp, 1979, pp. 237-238.

14 Mehdi Ghouirgate, L'ordre almohade (1120-1269): une nouvelle lectura anthropologique L'ordre almohade (1120-1269): une nouvelle lecture anthropologique, Toulouse, Université de Toulouse, 2011. Ver en: http://www.theses.fr/2011TOU20094 y María Isabel Fierro, "Algunas reflexiones sobre el poder itinerante almohade”, e-Spania, 8 (2009), edición electrónica. 
También la Primera Crónica General se hace eco del particular aprecio del rey castellano Alfonso VIII hacia su nueva conquista:

"Et despues que fue suya et en su poder deste noble rey don Alffonsso de Castiella, guarnesçiola de todas la cosas que menester fueron: et fizola ciudad real quel ella merescie; assento en ella catedra de la fe, esto es siella del obispo de la ley de Cristo; exalto en ella nombre de obispo; ayunto en ella pueblos de muchas partes, et fizo y pueblo de grandeza establecio en ella fortaleza de firmedumbre, et onrro en ella palaçio de fermosura; diol aldeas que fuessen suyas; ensanchola de muchos pastos; alço en alto los muros della, çercola de fortaleza segur; et crescio ella en ciudad de muchedumbre, ensanchada en términos de pueblos"15.

El suma, tras la conquista, el rey pondría todo su empeño en consolidar su adquisición, tomando para ello varias iniciativas fundamentales que decidirán el destino de Cuenca:

- Convertirla en ciudad realenga, protegiéndola así de posibles intereses señoriales.

- Promover su conversión en sede episcopal, lo que, por sí mismo, daba a la ciudad una entidad prominente en un amplio espacio geográfico en donde las ciudades episcopales más próximas quedaban relativamente lejos: Albarracín, Sigüenza y Toledo, frente a las que habría de hacerse sitio en los años venideros.

- Impulsar su repoblación, haciendo venir gentes de diversas procedencias, labor que no resultaría nada fácil si tenemos en cuenta las quejas de escasez poblacional conquense todavía un siglo después.

- Dotarla con un término, formado por diversas aldeas, que le aseguraran un patrimonio comunal suficiente y un área de influencia que propiciase las actividades económicas y, con ello, la prosperidad de la ciudad.

- Asegurar su posición defensiva con nueva muralla y fortaleza que la pusiera al abrigo de los vaivenes de la frontera.

En el comienzo del Fuero de Cuenca se alude con orgullo a la predilección de Alfonso VIII por su nueva conquista:

"Transcurridos nueve meses, hizo su entrada en la ciudad de Cuenca, prefiriéndola a las demás, ya que eligió a Cuenca como alphonsipolis, la prefirió para residencia suya y adoptó a sus ciudadanos como pue-

15 Primera Crónica General, edición de Ramón Menéndez Pidal, Madrid, Gredos, 1977, II, cap. 999, p. 679. 
blo predilecto, para consolidar hacia la prosperidad, libre y distinguida entre las demás, a la que habia librado de la cautividad de Babilonia y del yugo del faraón con las armas de su poder regio, una vez suprimida la inmudicia de la idolatría"l.

No hay nada de excepcional en estas afirmaciones, casi todos los reyes convertían en su ciudad predilecta a su última conquista. Pero lo que sí importa destacar es que el rey contempló la incorporación de Cuenca, no como la ocupación de una plaza más con indudable valor militar, sino como el centro de todo un territorio de enorme valor estratégico en aquellos momentos.

Desde esta óptica regia, la política de consolidación de la nueva conquista pasaba necesariamente por convertir a la ciudad en sede episcopal, en cuanto que se entendía que tal factor podía jugar un papel decisivo en orden a conseguir los otros objetivos que se acaban de enumerar.

\section{B) LA FUNDACIÓN EPISCOPAL.}

Buena prueba de que la conversión de Cuenca en sede episcopal se constituye en objetivo prioritario para el rey es que, ya antes de que se hubiera producido bula pontificia fundacional alguna, encontramos en la documentación real de Alfonso VIII la referencia a un obispo electo conquense por la sola iniciativa del rey, debiéndose producir tal designación seguramente de manera inmediata a la conquista de la ciudad, recayendo precisamente tal nombramiento, a buen seguro, no por casualidad, en un hijo y sobrino de dos caballeros que se habían distinguido en la toma de la ciudad.

En efecto, ya en el año 1178 aparece don Juan Yánez en los documentos reales actuando como confirmante como "primus conchanus electus", o como "Conche ecclesie prothoelecto", debiendo esperar a 1183 para que aparezca como "conchensis episcopus" ${ }^{\prime \prime}$, es decir, como obispo de pleno derecho, tras la obtención de las correspondientes bulas pontificias fundacionales. Este desfase no impediría que el electo conquense tuviera, a la espera de la bula fundacional, pleno reconocimiento pontificio, apareciendo como tal electo en una comisión pontificia encargada por Alejandro III ya en $1179^{18}$.

16 Fuero de Cuenca, edición de Alfredo Valmaña Vicente, Cuenca, Editorial Tormo, 1978, p. 33.

17 Con tal título aparece ya como confirmante de un documento real referido a los collazos de la Iglesia de Toledo de fecha de 6 de agosto de 1183, tal como se recoge en: Tomás Muñoz y Romero, Colección de fueros municipales y cartas pueblas de los reinos de Castilla, León, Corona de Aragón y Navarra, Madrid, Atlas, 1978, pp. 386-387.

18 Jorge Díaz Ibáñez, La iglesia de Cuenca en la Edad Media (siglos XII-XV). Estructura institucional y relaciones de poder, Tesis Doctoral, Universidad Complutense de Madrid, 1996, I, p. 116, puede consultarse en http://eprints.ucm.es/2445/; del mismo autor, Iglesia, sociedad y poder en Cas- 
A través de las correspondientes bulas pontificias del papa Lucio III dirigidas al rey y al nuevo electo, de fecha insegura, puesto que no se indica el ańo, pero probablemente de 1 de junio de 1182, quedaba definitivamente legalizada la fundación de la nueva sede episcopal, completándose el acto fundacional con otra bula de 15 de mayo de 1183 con la que se autorizaba al obispo conquense a constituir el correspondiente cabildo catedralicio que garantizase la debida atención religiosa y administrativa de la nueva dióce$\operatorname{sis}^{19}$.

Así, con el nombramiento de Juan Yánez como obispo conquense, las bulas fundacionales de la nueva sede y la autorización para la constitución del nuevo cabildo, en 1183 quedaban completados los actos jurídicamente fundamentales para la plena legalización canónica del obispado conquense.

En todo este proceso fundacional los intereses de los arzobispo de Toledo habían jugado un papel no poco importante. Con el avance de la reconquista al sur del Tajo, las pretensiones de primacía eclesiástica peninsular toledana habían ido creciendo, hasta ser reconocidas en el IV Concilio de Letrán ${ }^{20}$, en tiempos del arzobispo Jiménez de Rada, concibiendo el proyecto de identificar los límites de su influencia en el futuro con el avance máximo que alcanzara la frontera del reino castellano, lo que significaba situar su horizonte oriental en los mismos límites con Aragón, no por una expansión directa de la archidiócesis toledana, sino por la creación de nuevas diócesis sufragáneas de Toledo, de manera que si no se expandía la diócesis toledana, sí lo hacía su metrópoli o provincia eclesiástica en la que quedaban integradas estas nuevas fundaciones.

Sin embargo, ante la necesidad de legitimar tal pretensión, era necesario partir de algún fundamento jurídico-histórico, lo que vino dado por un documento, hoy tenido por falso, conocido como la División de Wamba, en la que se suponía quedaba recogido el mapa eclesiástico del antiguo reino visigodo sobre el que debía inspirarse el proceso de restauración o de fundación episcopal, según el caso, al hilo de las conquistas cristianas sobre el Islam² .

Con la base de la División de Wamba, se justificó la fundación de la diócesis de Cuenca como la sucesora de las antiguas sedes de Valeria y Ercábica, núcleos de población entonces desaparecidos. En cambio, nada se dijo de la antigua sede

tilla. El obispado de Cuenca en la Edad Media (siglos XII-XV), Cuenca, 2003, pp. 28-33.

19 Sobre este periodo fundacional y sus aspectos institucionales: José Manuel Nieto Soria, "La fundación del obispado de Cuenca, 1177-1183,. Consideraciones político-eclesiásticas", Hispania Sacra, XXXIV (1982), 111-132 y Antonio Chacón Gómez-Monedero, "Las bulas de fundación del obispado de Cuenca”, Cuenca. Revista de la Excma. Diputación Provincial, 25-26 (1985), 101-115.

20 Véase al respecto: Juan Francisco Rivera Recio, "La primacía eclesiástica de Toledo en el siglo XII", Anthologica Annua, 10 (1962), 11-87.

21 Luis Vázquez de Parga, La división de Wamba, Madrid, Consejo Superior de Investigaciones Científicas, 1943. 
de Segóbriga, utilizada para justificar la dependencia de Albarracín respecto de Toledo, a pesar de las reivindicaciones metropolitanas de Tarragona. Nada podía alegarse ahora respecto de Segóbriga con relación a Cuenca, pues de hacerlo habría podido impugnarse la dependencia de Albarracín con Toledo a favor de Tarragona ${ }^{22}$.

De este modo, no cabe duda de que, en los orígenes de la Iglesia de Cuenca, estuvieron detrás como impulsores decisivos los intereses políticos del rey castellano, que veía en la constitución de una sede episcopal un factor importante de consolidación de su política conquistadora y repobladora, y los intereses eclesiásticos Toledanos, cuyos arzobispos veían en la nueva sede una etapa más en sus proyectos de primacía, encontrando ambos intereses, en perfecta alianza entre ellos, el necesario respaldo pontificio a sus iniciativas. Pero esta entente rey-arzobispo irá más allá del mero hecho de la fundación de la nueva sede, haciéndose presente en particular en lo relativo a la elección de los primeros obispos de Cuenca.

\section{LOS PRIMEROS OBISPOS CONQUENSES Y LA ORGANIZACIÓN DE LA DIÓCESIS.}

\section{A) LOS PRIMEROS OBISPOS.}

Lo que acabo de señalar interesa destacarlo sobre todo para dimensionar mejor el papel de los hombres que actuaban como principales responsables de aquellas actividades: los primeros obispos de las nuevas diócesis. Es curioso observar cómo, a pesar de tratarse de personajes cuya acción fue tan decisiva para la historia de una ciudad y de un territorio, en general, el nivel de información que es posible obtener sobre ellos resulta siempre muy precario, con lo que su caracterización biográfica queda inevitablemente comprometida.

En cualquier caso, con lo recién apuntado es fácil suponer que estamos ante personajes de valía excepcional, cuya promoción al episcopado, casi siempre respaldada por el rey, no era fruto de la casualidad, sino de decisiones necesariamente muy sopesadas en las que los monarcas sabían que no estaban decidiendo tan sólo la promoción personal de un eclesiástico, sino la suerte de todo un territorio y el éxito definitivo de múltiples esfuerzos y empeños que generalmente habían supuesto el sacrificio de no pocas vidas, así como cuantiosos gastos.

Refiriéndome al caso concreto de los dos primeros obispos conquenses, don Juan Yáñez y san Julián, es curioso observar la presencia de unos rasgos comunes a ambos que hacen pensar que en su designación y actividad estuvieron presentes las circunstancias que acabo de indicar, siendo, en consecuencia, su aportación absolutamente decisiva a la consolidación de la nueva sede episcopal. 
Entre estos rasgos comunes convendría destacar los siguientes:

1) Tanto en el caso de Juan Yáńez, como de san Julián, parece que la designación se produciría de mutuo acuerdo entre el rey y el arzobispo de Toledo. No podía ser de otra manera. Alfonso VIII sabía que el nombramiento de estos prelados podía afectar y mucho al éxito efectivo de una conquista que había sido difícil y costosa ${ }^{23}$. Su criterio debía pesar mucho, siendo conocido el interés del monarca en configurar un episcopado lo más afín posible ${ }^{24}$. A su vez, partiéndose de la idea de la vinculación como sufragánea de Cuenca a Toledo, no podía ignorarse el criterio del arzobispo.

2) Tanto uno como otro pertenecen a familias mozárabes toledanas. Juan Yáñez a la familia de los condes de Peranzures, con importantes posesiones en Toledo, de donde eran naturales, y san Julián a la familia de los Tauro, menos conocida, pero también de mozárabes toledanos ${ }^{25}$. El reconocimiento social en la época de los mozárabes y, en particular, de los mozárabes toledanos, era grande. Estos mozárabes de Toledo de fines del siglo XII solían ser individuos que, ganada buena fama como laboriosos y abnegados, provenientes de familias que habían hecho frente a grandes dificultades, se mostraron particularmente inclinados a colaborar con el mayor empeńo, tanto con los arzobispos toledanos, como con el rey, ocupando cargos relevantes, tanto en la esfera eclesiástica como político-administrativa, destacando igualmente por su preparación cultural, formando un grupo con gran peso social y económico en la ciudad del Tajo $^{26}$. A ello se añadía un cierto aperturismo social en cuanto a sus actitudes, mostrándose dispuestos a relacionarse con gentes de procedencia diversa, incluidos judíos y musulmanes, a lo que contribuía en este último caso el que algunos conocieran el árabe.

3) También, tanto en un caso como en otro, ocupaban antes de ser obispos de Cuenca el mismo cargo. En efecto, tanto Juan Yáñez como san Julián eran miembros del capítulo catedralicio de Toledo, ocupando, además el cargo de arcediano de Calatrava. Miembros de la Iglesia toledana, sus cualidades serían bien conocidas del respectivo arzobispo.

23 Sobre la política de fundaciones episcopales de Alfonso VIII: Julio González, El reino de Castilla en la época de Alfonso VIIII, I, Madrid, Consejo Superior de Investigaciones Científicas, 1960, pp. 399-405.

24 Carlos de Ayala Martínez, "Los obispos de Alfonso VIII", Carreiras eclesiásticas no Occidente cristao (seculos XII-XIV), Lisboa, Fundaçao para a Ciênçia e Tecnologia, 2007, pp. 135-188.

25 Angel González Palencia, Los mozárabes de Toledo en los siglos XII y XIII, Madrid, Instituto de Valencia de Don Juan, 1930-34, I, doc. 274.

26 Reyna Pastor, "Problemas de asimilación de una minoría: los mozárabes de Toledo", Confictos sociales y estancamiento económico en la España Medieval, Barcelona, Ariel, 1973, pp. 196-268. 
El hecho de que fueran precisamente arcedianos suponía una posición que, tal como se definía por los canonistas del siglo XII, suponía una posición de quasi-obispos, en una época en que las funciones de este cargo se potenciaban muy notablemente en la actividad administrativa general de la diócesis, de modo que las tradiciones de muchos arcedianos en lo único que diferían del obispo es en que, realizando de hecho las mismas, éstas se referían a la circunscripción territorial y administrativa jerárquicamente inmediatamente inferior a la diócesis. Por último, el que ambos fueran también responsables, antes de llegar a Cuenca, precisamente, del arcedianato de Calatrava, también tiene su importancia ${ }^{27}$. Se trataba del territorio de la archidiócesis de Toledo militarmente más amenazado, aquel cuyo proceso de repoblación ofrecía más dificultades y que exigía, por tanto más atenciones. Desde ésta perspectiva, nada nuevo se iban a encontrar al llegar a Cuenca. Además, era el territorio más próximo, por el lado sur a la diócesis conquense, lo que establecía otro factor de familiaridad entre su experiencia previa y la que ahora afrontaban, por lo que, en principio, su designación parecía una apuesta segura, a la vez que una promoción natural de quienes tanto arzobispo como monarca bien se podían fiar.

Con relación a su vinculación con el cabildo catedralicio toledano previamente a su promoción al episcopado de Cuenca cabe, no obstante, observar cómo se muestra particularmente intensa en el caso de san Julián, al menos desde el punto de vista de lo que permiten comprobar los testimonios documentales que indican cómo incluso siendo ya obispo de Cuenca mantendría una apreciable relación con su antiguo cabildo catedralicio ${ }^{28}$.

De este modo, nos encontramos con lo que, siguiendo la expresión de Plutarco, podríamos considerar como dos vidas paralelas, que, por lo que se refiere a su gestión en Cuenca, resultaron altamente eficaces, tanto a corto como a largo plazo. Este paralelismo vital hace que en muchos aspectos convenga desarrollar una perspectiva conectada entre ambos personajes en función de los principales ámbitos de actuación a los que como prelados debieron hacer frente.

\section{B) SU ACTIVIDAD ORGANIZADORA.}

Cuando San Julián llega a Cuenca entre 1197 y 1198 se encuentra ya resueltos algunos problemas de no poca importancia, gracias a la gestión atenta de su predecesor. Así, Juan Yáńez había ejecutado lo siguiente ${ }^{29}$ :

27 Enrique Rodríguez-Picavea Matilla, "Aproximación a la geografía eclesiástica del arcedianato de Calatrava (siglos XII-XVI)”, Hispania Sacra, 43 (1991), pp. 735-773.

28 Véanse distintos testimonios documentales procedente de la catedral toledana referentes a san Julián en: Francisco J. Hernández, Los cartularios de Toledo. Catálogo documental, Madrid, Fundación Ramón Areces, 1985, docs. 264, 269, 276, 277, 280, 288, 289.

29 Análisis sistemático de la documentación relativa a estas iniciativas en: Díaz Ibáñez, Iglesia, sociedad y poder, pp. 71-73. 
- La constitución del nuevo cabildo catedralicio y su dotación económica (28 de julio de 1183), con la enorme importancia que tal institución tenía para el gobierno y organización de la diócesis. Dicho cabildo se mantendría todavía con san Julián como convento de canónigos regulares ${ }^{30}$.

- Se había preocupado, poniendo gran empeño en ello, en estrecha cooperación con Alfonso VIII, de todo lo referente a la dotación económica de la nueva diócesis, tanto en lo que se refería la llamada mesa episcopal como capitular. Consecuencia de ello es que haga un reparto muy pormenorizado de las rentas de la diócesis (16 de enero de 1195) ${ }^{31}$.

- Definió algunos señoríos episcopales dentro de la diócesis con la base de algunas fortalezas, sobre todo en el norte de la diócesis, que fueron enclaves decisivos en el proceso de repoblación, tales como los correspondientes a los castillos de Peńas Alcatenas y Peralveche ${ }^{32}$, así como los de Monteagudo y Paracuellos ${ }^{33}$.

- Establecería diversos acuerdos con la Orden de Santiago y algunos monasterios, sobre todo en materia de rentas decimales, evitando así conflictos para el futuro ${ }^{34}$.

- Quizá, acaso el 15 de agosto de 1195, según el Necrologio-Obituario de la catedral $^{35}$, tuvo lugar la dedicación del altar mayor de la catedral a Santa María ${ }^{36}$.

Siendo toda esta actividad importante y muy concentrada en pocos años, no fue impedimento para que el obispo Juan Yáñez atendiese también a sus deberes personales con respecto a un monarca como Alfonso VIII, cuya colaboración resultaría decisiva en todo este proceso de puesta en marcha de la nueva diócesis. Expresión de la operatividad de este vínculo entre obispo y monarca sería la asis-

30 Descripción detallada de su composición en: Díaz Ibáñez, Iglesia, sociedad y poder, pp. 30 y $133-155$.

31 Sobre todo este proceso de dotación económica de la nueva mitra episcopal y de su cabildo catedralicio: José Manuel Nieto Soria, "El equipamiento económico de una sede episcopal castellana de nueva creación: Cuenca 1180-1280", Anuario de Estudios Medievales, 12 (1984), 311-340 y Díaz Ibáńez, Iglesia, sociedad y poder, pp. 183-222.

32 Archivo Catedralicio de Cuenca, Estatutos, no 16, copia en Archivo Histórico Nacional, leg. 3190, no 3, fols. 10v-11v (24-II-1182).

33 Archivo Catedralicio de Cuenca, caja 1, leg. 3, no 26, copia en Archivo Histórico Nacional, leg. 3190, no 3, fols. 9v-10v (12-IV-1187).

34 Conviene destacar con relación a la Orden de Santiago el acuerdo alcanzado por Juan Yáńez en materia de diezmos, tal como se refleja en un documento sin fecha, probablemente dado entre 1190 y 1193 y que será enormemente determinante para la evitación de futuros conflictos en esta materia. Archivo Histórico Nacional, carp. 98, nº 2.

35 Sobre esta importante fuente para la historia local conquense José Trench i Odena, "El necrologio-obituario de la catedral de Cuenca: noticias históricas y crónica de la vida ciudadana", Anuario de Estudios Medievales, 12, (1982), pp. 340-363.

36 Díaz Ibáñez, Iglesia, sociedad y poder, pp. 72-73. 
tencia de aquél a las cortes celebradas en Carrión en $1188^{37}$.

De acuerdo con lo que se acaba de señalar, no fue poco lo que san Julián se encontró resuelto, lo que no impediría que llevase a cabo actuaciones decisivas para el futuro de la diócesis ${ }^{38}$ :

- Otorgamiento y confirmación en 1201 de los primeros estatutos capitulares conocidos, con lo que se establecía el texto regulador básico para la actividades del cabildo catedralicio (residencia, administración de rentas y patrimonio). Se trataba por sí mismo de un acto institucional de indudable relevancia, pero que, más allá de la misma, nos muestra ya la interacción entre hechos biográficos concretos y memoria que se concitan en este personaje, puesto que, en cuanto que en el documento aparece la suscripción autógrafa del prelado, ha sido elevado a la condición de verdadera reliquia $^{39}$.

- Donaciones a favor del capítulo catedralicio en Huete (1202) y Cañete (1207).

- Mediación para el establecimiento de acuerdos entre el cabildo y los clérigos parroquiales a fin de racionalizar las relaciones económicas, jurisdiccionales y jerárquicas entre cabildo y clero diocesano.

- Acuerdo con el concejo de Cuenca sobre los derechos de la jurisdicción eclesiástica en relación con los dependientes de los canónigos (concordia de 7 de marzo de 1207) ${ }^{40}$.

En función de estas iniciativas, puede afirmarse que la gestión de san Julián va dirigida en varios sentidos, todos ellos de indudable relevancia para la evolución futura de la diócesis, a saber: reconocer el protagonismo esencial del cabildo catedralicio en el proceso de institucionalización de la diócesis, facilitando el proceso para convertirlo, tal como se reconocía en el derecho canónico, en el colaborador inmediato del obispo; en coherencia con lo que se acaba de señalar, asegurar la base patrimonial del cabildo catedralicio, contribuyendo a ampliar sus propiedades, a costa de las pertenecientes a la mesa episcopal y, en cambio, reduciendo la aportación fiscal del clero diocesano en su mantenimiento, de manera que, a la vez que se favorecía al cabildo, se favorecía igualmente al clero parroquial; regular mediante las normas necesarias la vida clerical en la diócesis; alcanzar una relación armónica entre los diversos estamentos clericales; definir los aspectos económicos

37 Ana Arranz Guzmán, "Reconstrucción y verificación de las Cortes castellano-leonesas: la participación del clero", En la España Medieval, 13 (1990), pp. 33-132.

38 El seguimiento documental de estas actuaciones en: Díaz Ibánez, La iglesia de Cuenca en la Edad Media., I, 119-124.

39 El documento lo publica Miguel Jiménez Monteserín, Vere pater pauperum. El culto de san Julián en Cuenca, Cuenca, Diputación Provincial de Cuenca, 1999, pp. 405-406.

40 Pedro Izquierdo Gismero, Bibliografía sobre san Julián, segundo obispo y patrón de Cuenca, siglos XII-XXI, Cuenca, Diputación Provincial de Cuenca, 2009. 
y jurisdiccionales con la vista puesta en la evitación de futuros conflictos con otras instituciones y, finalmente, colaborar en el proceso de repoblación de la diócesis. Resumiéndose así el conjunto de directrices de san Julián en su gestión al frente de la diócesis. Mención aparte habrá que hacer de la implicación de san Julián en el impulso decisivo en el proceso constructivo de la nueva catedral ${ }^{41}$.

Al igual que en el caso de Juan Yáñez, nada de esta intensa dedicación a los asuntos propios de la actividad episcopal pareció suponer ninguna forma de distanciamiento con respecto al servicio regio, de lo que se ofrece algún testimonio documental en el que se da reflejo de una cierta relación de afecto personal del monarca hacia al prelado al que se dirige en alguna ocasión bajo la forma: "domno Juliano, karissimo ac venerabili amico meo" ${ }^{\prime 2}$.

\section{C) SU LABOR REPOBLADORA.}

Este último aspecto que he señalado, el de la repoblación, es decisivo desde todos los puntos de vista. Podían los reyes y los arzobispos de Toledo esforzarse mucho en buscar personas idóneas para la nueva sede episcopal, podían ser los prelados conquenses celosos y abnegados para sus obligaciones y buscar lo mejor para su clero, todo eso hubiera sido trabajo baldío si la repoblación, la ocupación del territorio no hubiera avanzado con ritmo mantenido a pesar de todas las dificultades. De este modo, tal asunto se convertía en quehacer central de aquellos primeros prelados conquenses, tal como se revela con precisión en algunas fuentes:

\section{"Tomó [el rey Alfonso VIII] los omes de la Extremadura e fizolos yr pobra Cuenca e Alarcón, e fizo de Cuenca obispado e ovo nombre el pri- mero obispo don Yanes, e pobró muy bien sus fronteras en derredor" ${ }^{243}$.}

Desgraciadamente, son bien pocas noticias las que tenemos que nos informen de manera directa sobre esta acción repobladora de los obispos, si bien cabe deducirla de muchas referencias indirectas como son las referidas a las posesiones episcopales en zonas de particular relieve repoblador y al otorgamiento real de rentas y nuevas posesiones a los obispos que, en cierta medida, habría que interpretar como consecuencia directa de la alta valoración que al rey merecía esta colaboración episcopal en actividad de tal relieve estratégico. ${ }^{44}$

En efecto, ya en tiempos de don Juan Yáñez y del obispo san Julián, los prela-

41 Jiménez Monteserín, Vere pater pauperum, pp. 39-42.

42 Julio González, El reino de Castilla en tiempos de Alfonso VIII, III, doc. 748, p. 311. Citado en Jiménez Monteserín, Vere pater pauperum, pp. 39 y 49.

43 Julio González, El reino de Castilla en la época de Alfonso VIII, I, p. 114.

44 Julio González, "Repoblación de las tierras de Cuenca", Anuario de Estudios Medievales, 12 (1982), pp. 183-204. 
dos conquenses obtuvieron, generalmente por donación regia importantes posesiones territoriales que, con frecuencia, reflejan en el propio texto de la concesión la obligación del obispo de promover en su entorno todo lo que se refiera a la actividad repobladora ${ }^{45}$.

Buena parte de estas donaciones se situaban preferentemente en el extremo noroccidental de la diócesis y en las inmediaciones del Tajo. Era claro que tanto para el rey como para la Iglesia de Cuenca, la consolidación de los avances al sur de Cuenca, pasaban por asentar población en la zona ya más segura por entonces de las proximidades del Tajo y que todavía debían contar con un poblamiento muy débil.

Se trata, en realidad, de una técnica repobladora habitual. Se conquista un punto fuerte y defendible, en este caso Cuenca, y entonces, cuando tal conquista ofrece nuevos márgenes de seguridad, se potencia la repoblación en tierras más septentrionales que actúan de reserva de retaguardia. Es como si se avanzase con un procedimiento de dos pasos adelante y uno atrás.

Frente a esa repoblación estratégica de más amplia dimensión, a la que seguramente dedicaron buena atención los primeros obispos conquenses, se unió en un nivel más localizado la repoblación en torno a las aldeas en las que el proceso de dotación real había dado lugar a la presencia episcopal, ya en lugares más próximos a la propia ciudad conquense como Avia $^{46}$ o Huerta ${ }^{47}$.

\section{San julián: un obispo para la memoria.}

Tal como se ha podido ver, nos hallamos ante dos trayectorias biográficas enormemente similares en su desarrollo, con hitos perfectamente parejos, sin embargo, la memoria, por distintas circunstancias hace su propia selección, resultando en este caso especialmente afortunada la figura de san Julián que acabará conectándose con la esencia originaria de la ciudad conquense cristianizada, para convertirse en su santo patrón y en una especie de símbolo de la identidad local.

Habiendo acaecido la muerte de san Julián el 20 de enero de 1208, según el Necrologio-Obituario ya aludido ${ }^{48}$, sería enterrado en la catedral, sin que su recuerdo parezca tener especial relieve hasta ya avanzado el siglo XV. Es en esta centuria

45 Sobre la actividad repobladora de los obispos y cabildo de Cuenca en el contexto del proceso de dotación de la nueva sede episcopal pueden encontrarse datos y análisis particulares en: José Manuel Nieto Soria, "El equipamiento económico de una nueva sede episcopal castellana de nueva creación: Cuenca, 1180-1280”, Anuario de Estudios Medievales, 12 (1982), pp. 311-340.

46 Concedida a la iglesia conquense por privilegio real de 24 de diciembre de 1183 . Archivo Catedralicio de Cuenca, caja 1, leg. 2, no 16; copia en Archivo Histórico Nacional, leg. 3190, nº. 3, fols. 5r-6r.

47 Concedida a la iglesia conquense por privilegio real de 14 de noviembre de 1183 . Archivo Catedralicio de Cuenca, caja 1, leg. 2, no 15; copia en Archivo Histórico Nacional, leg. 3190, nº. 3 , fols. $8 \mathrm{v}-9 \mathrm{v}$.

48 Trench i Odena, p. 371. 
cuando desde el cabildo catedralicio comienza a fomentarse un cierto culto a su memoria. Éste parece ser resultado del empeño particular del cabildo catedralicio que, por su propia iniciativa, dará lugar a celebraciones cultuales específicas, primero en 1447, y luego de nuevo en 1471, actuando como hitos decisivos en el camino a la transformación del prelado en santo patrón de la ciudad, con la correspondiente celebración de una procesión en su honor que tendría lugar en adelante el 28 de enero de cada año ${ }^{49}$. A la vez, en torno a su sepulcro, sin que se pueda afirmar con precisión el origen de tal creencia, pero acaso con anterioridad a la que se acaba de indicar, ya comenzó a reconocerse una cierta significación taumatúrgica al lugar donde se hallaba su sepulcro.

Así, sólo a partir de 1471 , comenzó a tener cierta presencia el culto a san Julián, celebrando el cabildo una fiesta anual con procesión todos los 28 de enero. En la noche del 17 de enero de 1518 se produciría en presencia del cabildo catedralicio y de diversos notables de la ciudad la solemne apertura del viejo sepulcro en el que había estado depositado san Julián durante más de trescientos años. Los testimonios que dan los presentes en aquella apertura del sepulcro son bastante reiterativos ${ }^{50}$ en el sentido de poner de relieve el agradable olor que todos los asistentes habrían percibido al levantar la losa que lo cubría, aludiendo unos a un olor como de ámbar ${ }^{51}$ y otros como de árbol del paraíso ${ }^{52}$, coincidiendo, en cualquier caso en la placentera sensación que les producía, apreciándose, además, el estado de incorruptibilidad del cuerpo. Tampoco faltaban en las testificaciones algunas manifestaciones de curaciones que se ponían en relación con el sepulcro del obispo $^{53}$, lo que unido a otros precedentes taumatúrgicos, impulsaría definitivamente el culto, por lo que se procedería a construir una capilla en honor al prelado, a la que se trasladarían sus restos. A la vez, se generaría un cierto flujo peregrinatorio a su tumba que daría lugar a la difusión de noticias sobre supuestos milagros, si bien parece que tales peregrinaciones serían de muy corta duración, no yendo más

49 Jiménez Monteserín, Vere pater pauperum, p. 284.

50 Estas testificaciones referidas a la apertura del sepulcro las publica Jiménez Monteserín, Vere pater pauperum, pp. 418-531.

51 Testimonio de Pedro de los Ríos, inquisidor: "y este testigo se llegó, así como acabaron de alçar la piedra de encima, obra de un palmo et myró la disposición del cuerpo y, así commo se apartó del túmulo, dióle un tan grand olor a manera de olor de ámbar líquido, que segund el romadizo [que] tenía este testigo, lo touo por cosa muy marauyllosa sentir olor ninguno; y quando este testigo sintió el dicho olor los hombres que estauan levantando la piedra dixieron asimismo a vozes, commo sentian grandísmo olor, et lo mismo dixeron otras munchas personas que alli se fallaron". Ibid. p. 418.

52 Testimonio de Andrés de Vergara: "que cuando fue alçada la piedra, sallyó un ayre del dicho sepulcro que le parece que matara una candela e un olor como de árbol de paraíso (...) e a todos oyó decir commo olía muy bien". Ibid., p. 418.

53 Así, el testimonio de maestre Diego de Flandes, entallador vecino de Cuenca, que relata la curación de su rodilla derecha tras presenciar la apertura del sepulcro de san Julián. Ibid., pp. 418-419. 
allá del propio año 1518. También, se encargaron distintas inscripciones destinadas a la catedral exaltando el recuerdo del prelado ${ }^{54}$. En 1530 ya se había tomado la iniciativa de reclamar la canonización del obispo conquense $e^{55}$, lo que dos años después contó con la adhesión personal de Carlos $\mathrm{V}$ a esta solicitud, refiriéndose ya el monarca al prelado como autor de "muchos e grandes milagros" ${ }^{\text {". }}$. Queda detallada constancia documental, según acta catedralicia del 16 de septiembre de $1595^{57}$, de las extraordinarias y solemnísimas celebraciones festivas habidas el 5 de septiembre de 1595 para conmemorar la canonización del santo para las que el obispo del momento, Juan Fernández Vadillo, proveería de cien hachas de cera, a la vez que dotó a veinte doncellas huérfanas con 50 ducados cada una. Por su parte, el cabildo hizo a su costa un arco triunfal de tres ojos, de 37 pies de alto y 20 de ancho, el ojo central, y de 24 de alto y 15 de ancho los laterales, que se ubicaría en la Plaza Mayor, junto a la catedral. Las celebraciones religiosas y profanas se sucedieron por toda la ciudad, no faltando ni procesiones, ni exhibición de pinturas alusivas a la vida del santo, ni representaciones teatrales sobre el mismo tema, junto con otras muchas expresiones de devoción y alegría popular "con grande contento y rregocijo de todos", de modo que "todo se hizo a gloria de Dios con grande conformidad y paz, en que se hechó de uer que todos heran mouidos del çelo de çelebrar dignamente la fiesta y triunpho de un tan gloriosso sancto's8.

De este modo, se había pasado de una biografía apenas circunscrita a los asuntos propios de una práctica institucional de carácter administrativo que apenas deja entrever un conjunto de documentos, en su mayor parte, bajo la forma de otorgamientos regios, a la construcción de una memoria hagiográfica de gran proyección popular que, en palabras de su principal estudioso, el Doctor Jiménez Monteserín, habría dado lugar a la consecución de "un santo obispo para una diócesis huérfana" ${ }^{259}$.

El culto y la devoción hacia el personaje se verán además favorecidos desde fines del siglo XVI por el impulso de toda una literatura apologética frecuentemente carente de fundamento histórico seguro y especialmente coincidente en reivindicar determinadas virtudes del prelado sobre todo alusivas a su atención a los pobres y a la dedicación al cuidado de sus feligreses afectados por supuestos brotes pestíferos durante su pontificado, estableciéndose así un prototipo de santo obispo ${ }^{60}$. Entre esta literatura apologética juliana tienen lugar propio un buen

54 Izquierdo Gismero, pp. 31-32.

55 Memorial de los gastos para la canonización de san Julián en: Izquierdo Gismero, p. 35.

56 Ibid., p. 36.

57 El documento lo publica Jiménez Monteserín, Vere pater pauperum, pp. 546-548.

58 Otra descripción más breve de las mismas celebraciones en: ibid., pp. 549-551.

59 Con estas palabras titula el capítulo en que con todo detalle se puede seguir la peripecia de este proceso de construcción hagiográfica. Jiménez Monteserín, Vere pater pauperum, pp. 279-324.

60 Un análisis riguroso y del mayor interés de los orígenes del culto a San Julián, plenamente 
número de autores, generalmente conquenses, imbuidos de la devoción hacia su santo patrón: Francisco Escudero (1589) ${ }^{61}$, Bartolomé de Segura (1599) ${ }^{62}$, Juan Bautista Valenzuela Velázquez $(1611)^{63}$, Fray Antonio de Santa María (1686) ${ }^{64}$, Bartolomé Alcázar (1692) ${ }^{65}$. A estas obras se podrían añadir otras de menor interés producidas durante el siglo XVI, como momento decisivo de recreación literaria del personaje ${ }^{66}$, hasta remontarnos incluso hasta el propio siglo $\mathrm{XX}^{67}$. En esa construcción de la memoria literaria no había diques de contención a la imaginación, lo que permitía crear extensos anecdotarios de lo más variopinto en donde abundaban las manifestaciones milagrosas y los ejemplos de abnegación ejemplar del santo. A la vez, la invención y la inexactitud se convertían en la tónica habitual, lo que, por ejemplo, permitía a Baltasar Alcázar remontarse al IV Concilio de Letrán de 1215 o, como muy tarde, según el mismo autor, al I de Lyon, para situar el momento originario de la canonización del santo, sin que, en realidad, ninguna noticia precisa permitiera autorizar tales referencias cronológicas ${ }^{68}$. Del mismo modo, esta literatura apologética nos lo presentará haciendo cestillos de mimbre con sus propias manos para alimentar a los indigentes de la ciudad con las rentas obtenidas, o dando numerosas pruebas de abnegación, atendiendo a los enfermos durante el brote pestífero que, supuestamente habría afectado a Cuenca en 1207 , sobre lo que no cabe alegar prueba histórica segura alguna.

\section{Conclusiones: de Obispos fundadores a OBISPOS SANTOS PATRONOS}

A la vista de los dos casos estudiados, dos prelados que bien podemos considerarlos en muchos aspectos como adecuados al modelo de obispo fundador por su actividad desarrollada, podemos constatar los caprichosos resultados de la relación entre biografía y memoria.

integrado en el contexto histórico de la época en que comienza a manifestarse puede encontrarse en: Miguel Jiménez Monteserín, "Notas de sociabilidad religiosa: el culto a san Julián en Cuenca", Ciudad de Cuenca, 96 (1992), pp. 3-31.

61 Vida y milagros del glorioso confesor San Julián, segundo obispo de Cuenca... Ansí mismo la vida de don Nuño Alvarez, chantre y canónigo de la Santa Iglesia de Cuenca, Cuenca-Toledo, 1589.

62 Del nacimiento, vida y muerte, con algunos particulares milagros, del glorioso confessor San Julián, segundo obispo de Cuenca, Cuenca, 1599.

63 Discurso en comprobación de la santidad de la vida y milagros del glorioso San Julián, segundo obispo de Cuenca, Cuenca, 1611.

64 Vida de San Julián, obispo y patrono de Cuenca, y del ilustrísimo y Reverendísimo Señor don Enrique Pimentel, obispo de aquella Santa Iglesia, Alcalá de Henares, 1686.

65 Vida, virtudes y milagros de San Julián, Madrid, 1692.

66 Izquierdo Gismero, pp. 59-61.

67 Rogelio Sanchíz Catalán, Noticia del culto tributado a San Julián, segundo obispo de Cuenca, Cuenca, 1909 o Juan José Bautista Martínez, Biografía de San Julián, Cuenca, 1945.

68 Balthasar Alcázar, Vida,virtudes y milagros de San Julian segundo obispo de Cuenca, Madrid, Imprenta de Juan García Infanzón, 1692, pp. 404-405. 
Dos vidas paralelas, de muy similar actividad, de un origen y vías de promoción igualmente próximas, pero, en cambio, generadoras de significaciones completamente distintas y no tanto por la realidad biográfica concreta, sino por la reelaboración a posteriori de ésta.

Si nos atenemos a la estricta información biográfica documentalmente comprobable, el tipo de iniciativas y actividades resultan harto coincidentes y perfectamente comparables a lo que, de hecho, la documentación nos permite afirmar con respecto a la inmensa mayoría de tantos obispos de aquellas centurias que, llegados a una nueva sede episcopal recién fundada, tras la conquista del lugar, se debían enfrentar a la compleja labor de poner en pie toda la estructura eclesiástica y administrativa propia de una diócesis. Es por ello que, en el caso de Juan Yánez, como en el caso de san Julián, los documentos, como en el caso de tantos otros obispos del momento, delimitan una narración biográfica que nos sitúa ante hitos similares:

- La frecuente proximidad al rey, avalada por alguna intervención en algún acto regio.

- La cercanía, en la mayor parte de los casos, al metropolitano correspondiente.

- La constitución del nuevo cabildo catedralicio, en el caso del primer obispo de la diócesis, seguido de distintas iniciativas en materia de reforma de su perfil jurídico y administrativo que dejan su rastro en distintos estatutos capitulares.

- La dedicación al proceso de dotación económica y patrimonial de la nueva sede, en el que con frecuencia se refleja la mayor o menor habilidad para atraer la colaboración hacia esta actividad mediante la plasmación de la misma en donaciones y privilegios.

- La puesta en pie de una organización parroquial en el marco de la ciudad episcopal, que se ve luego perfeccionada, a la vez que se toman iniciativas similares para el conjunto de la diócesis.

- La participación reivindicativa en conflictos resultantes de la necesidad de afirmar la autoridad episcopal frente a otras instancias institucionales tanto laicas, sobre todo los concejos, como eclesiásticas, tales como otras sedes episcopales limítrofes, órdenes religiosas y militares, o monasterios.

- La implicación personal en procesos de repoblación que con frecuencia resultan enormemente relevantes para la afirmación territorial de las nuevas conquistas.

- Ocasionalmente, la participación en algún concilio o la convocatoria de algún sínodo, por lo común, muy limitadamente documentado para el contexto de la cronología aquí considerada.

En definitiva, trayectorias biográficas en donde, con frecuencia, las variaciones apenas se reducen al cambio de homónimos o topónimos. Sin embargo, a veces, 
circunstancias extrabiográficas acaban imponiendo una diferencia decisiva, tal como ocurre en los personajes considerados.

En un caso, el de Juan Yáñez, su imagen acaba quedando reducida a la frialdad de una documentación limitada a la mera práctica institucional propia del cargo que establece riguroso límite a cualquier intento de perfil biográfico cuyo modelo responde al conjunto de materias e iniciativas que acabamos de describir.

En el otro, el de san Julián, una biografía similar que se acaba convirtiendo varios cientos de años después de su muerte en hagiografía, como consecuencia de intereses particulares completamente ajenos al propio marco biográfico. Así, el individuo acaba elevado por encima de su realidad documental para transformarse en símbolo de identidad, en memoria colectiva, desbordando los propios límites del relato biográfico comprobable, mostrando de este modo los inesperados efectos que puede desencadenar la relación entre biografía y memoria. 
